\title{
Analysis of the Hybrid of Mudar/Snake Grass Fiber-Reinforced Epoxy with Nano-Silica Filler Composite for Structural Application
}

\author{
I. Jenish $₫{ }^{1},{ }^{1}$ A. Felix Sahayaraj $\odot,^{2}$ V. Suresh $\odot,{ }^{3}$ J. Mani raj, ${ }^{2}$ M. Appadurai $\oplus,{ }^{4}$ \\ E. Fantin Irudaya Raj $\left(\mathbb{D},{ }^{5}\right.$ Omaima Nasif, ${ }^{6}$ Saleh Alfarraj, ${ }^{7}$ and Ashok Kumar Kumaravel ${ }^{8}$ \\ ${ }^{1}$ Department of Applied Mechanics, Seenu Atoll School, Hulhu-medhoo, Addu City Postal Code 19060, Maldives \\ ${ }^{2}$ Department of Mechanical Engineering, Kalaignar Karunanidhi Institute of Technology, Coimbatore 641402, Tamilnadu, India \\ ${ }^{3}$ Department of Biotechnology, Sharafuddin School, Hithadhoo 19020, Maldives \\ ${ }^{4}$ Department of Mechanical Engineering, Dr. Sivanthi Aditanar College of Engineering, Tuticorin 628215, Tamilnadu, India \\ ${ }^{5}$ Department of Electrical and Electronics Engineering, Dr. Sivanthi Aditanar College of Engineering, Tuticorin 628215, \\ Tamilnadu, India \\ ${ }^{6}$ Department of Physiology, College of Medicine and King Khalid University Hospital, King Saud University, Medical City, \\ PO Box-2925, Riyadh 11461, Saudi Arabia \\ ${ }^{7}$ Zoology Department, College of Science, King Saud University, Riyadh 11451, Saudi Arabia \\ ${ }^{8}$ School of Chemical Engineering \& Bio-Engineering University of Ulsan, Ulsan 680749, Republic of Korea \\ Correspondence should be addressed to V. Suresh; suresh.velse@sharafuddin.edu.mv
}

Received 29 September 2021; Accepted 2 November 2021; Published 5 January 2022

Academic Editor: P Ganeshan

Copyright ( $\odot 2022$ I. Jenish et al. This is an open access article distributed under the Creative Commons Attribution License, which permits unrestricted use, distribution, and reproduction in any medium, provided the original work is properly cited.

\begin{abstract}
Natural fiber composite materials are competent materials that may replace conventional synthetic materials where the strength to weight ratio is essential. In this paper, the mechanical characteristics of composites made up of randomly oriented natural fibers (mudar fiber and snake grass fiber) with nano-silica filler are detailed for the first time. From the various literature surveys, the critical length of mudar and snake grass fiber is chosen as $40 \mathrm{~mm}$ and $30 \mathrm{~mm}$, respectively. The test samples were prepared with a fiber content of $10 \%, 20 \%, 30 \%$, and $40 \%$ with an equal amount of mudar and snake grass fiber. The percentage of nano-filler is maintained as constant as $3 \%$ with all the compositions. The composites showed that the highest mechanical properties were found at $30 \%$ fiber volume. The maximum tensile strength is $45 \mathrm{MPa}$, and the flexural strength is $51 \mathrm{MPa}$. The maximum impact strength is $4.5 \mathrm{~J}$. Sample ID 3 provided the best results compared to other proportions. The fiber/matrix adhesion was investigated using a scanning electron microscope (SEM). These predominant mechanical properties make it easier for the implementation of the prepared composite material in structural and automotive applications.
\end{abstract}

\section{Introduction}

The mechanical properties of the natural fiber polymer composites depend on several factors, such as single fiber strength, average fiber length, and fiber-matrix adhesion. Strong interfacial bonding is necessary for optimal stress transmission between fiber and matrix [1-3]. The resistance to moisture-induced deterioration of the matrix-fiber adhesion was improved by surface treatment of fiber [4]. The mechanical properties of natural fiber-reinforced polymer composites are significantly influenced by certain manufacturing processes [5]. Natural fibers, particularly jute, hemp, flax, and kenaf, have excellent mechanical characteristics and may be able to compete with glass fiber in terms of specific strength and modulus [6]. Several kinds of research were done on the variety of natural fibers, including jute, hemp, sisal, and kenaf, to see 
how they affect the mechanical characteristics of composite materials [7]. Bast fibers are derived from the outer cell layers of diverse plant stems and account for one-third of the total weight. Bast fibers are a collection of fiber bundles. To improve finer fiber extraction, these bundles are physically or chemically broken down. The filaments are comprised of cellulose and hemicellulose and are held together by a lignin or pectin matrix. Purely natural bast fibers come from the vascular tissue or outer bark of jute, kenaf, flax, and hemp plants and are strong cellulosic fibers [8]. The flax fibers were extracted from the bast or skin of the plant. Flax fibers are smooth, less dense, and flexible, and bundles of fiber resemble blonde hair, thus the term "flaxen" [9-12]. The banana fiber composite is ductile, requiring little plastic deformation [13]. Pandanus plant fiber is easily accessible and has higher fiber content [14]. Incorporation of nano-silica increased the mechanical properties without increasing the density of the composite materials [15]. The stiffness of the matrix is increased by adding nano-silica which leads to transferring the load easily from matrix to fiber, so automatically, the properties of the composite material are improved [16]. The tensile (tensile strength/modulus) and flexural (tensile strength/modulus) properties are increased by adding 3 wt.\% of nano-silica with epoxy hybrid composite [17]. Natural fiber characteristics are determined by their chemical components [18], which are determined by the geological conditions in which they were found. The amount of cellulose in natural fiber determines its strength [19]. Characteristics like fiber selection and the matrix used during processing influence the characteristics of natural fiber-reinforced composites [20]. The bonding between the fiber and the matrix determines the strength of the processed natural fiber composite, which is affected by surface shape [21]. Kevlar and Napier grass fibers are bonded with epoxy matrix to create a novel composite utilizing a traditional hand layup fabrication method, and five different sequences are fabricated to measure the mechanical properties of this hybrid composite laminate [22]. Thus, natural fibers are regarded as the suitable reinforcement in material industries for better development. In this article, hybrid of mudar/snake grass fiber-reinforced epoxy composite particulate-filled with silica nano-powder has been fabricated, and the mechanical properties of the fabricated samples are discussed. As it has a substantial load carrying capacity, obligating a preferable structural application would give the value of this material.

\section{Materials and Methods}

The raw materials used in the fabrication of hybrid composites are mudar fiber (Calotropis gigantea), snake grass (Sansevieria ehrenbergii), nano-silica, epoxy resin (LY 556), and hardener (HY 951). The epoxy resin has the density of $1.11 \mathrm{~g} / \mathrm{cm} 3$ and Young's modulus of $3400 \mathrm{MPa}$. Moreover, it has the failure stress and strain value of $95 \mathrm{MPa}$ and $3 \%$. The composite fabrication process is shown in Figure 1. The properties of the fibers are given in Table 1 .

2.1. Mudar Fiber. The fibers were collected from the Kanyakumari region, Tamil Nadu, India. The fine, robust fibers that predominate throughout the plant make it useful. The scientific name of the plant is Calotropis gigantea. To get them, the straightest branches are cut and left to wither for at least twenty four hours; the skin is then peeled and the stringy part between the bark and the inner layer is removed on the second and third days. They are then exposed to the sun to dry. This method is time-consuming and costly, but soaking the bark in water causes it to decompose the layers, and cutting it will ruin it. The fiber may be separated as finest fiber for the useful work. It can withstand water for a long period. Then, it is dried at $70^{\circ} \mathrm{C}$ in an oven. The plant is illustrated in Figure 2, and extracted fiber is shown in Figure 3.

2.2. Snake Grass Fiber. Snake grass fibers were extracted from leaves of the Sansevieria ehrenbergii plant from local parts of Kannampalayam village, Coimbatore, India. Snake grass has several physical characteristics that make it more ideal for spinning finer counts, including length, strength, and uniformity. The fiber has been extracted through the microbial degradation technique. Figures 4 and 5 show the plants and fiber images.

2.3. Nano-Silica. The nano-silica is not very expensive and easily available in most of the shops and also easy to transport. But, it must be neatly packed during transport because the size is in nano-scale. The nano-silica was bought from Astrra Chemicals, Chennai. The size of the powder is $15-80 \mathrm{~nm}$. The colour is pure white. Special care was taken during material preparation time because it easily spreads over the air. The normal and SEM images of the nano-silica are given in Figures 6(a) and 6(b).

2.4. Epoxy Resin. Epoxy (LY 556) was obtained from Covai Seenu Chemicals, Coimbatore, Tamil Nadu, India. The epoxy resin is coupled with catalyzing ingredients to form polyepoxide which is in the form of polymers and crosslinks. The viscosity of the mixture and its shrinking properties are influenced by epoxy resin and additives. The number of fillers and diluents used will affect the resin system's physical and handling qualities.

2.5. Hardener. The hardener (HY 951) is being utilized was supplied by Covai Seenu Chemicals, Coimbatore, Tamil Nadu, India. These hardeners react with the epoxy resins and have a significant impact on the ultimate properties of the cured epoxy resin system. Epoxy with hardener blending provides significant properties of gel time, combined viscosity, and demold time. Epoxy hardeners have an impact on the physical characteristics of epoxy resin systems, such as tensile, compression, and flexural qualities.

2.6. Mold Design for Specimen Preparation. The composite plates with mudar and snake grass hybrid fibers as reinforcement were prepared with the dimension of $300 \mathrm{~mm} \times 150 \mathrm{~mm} \times 3 \mathrm{~mm}$, as shown in Figure 7. Steel plates were used to create the mold. For non-sticking purposes, Teflon 


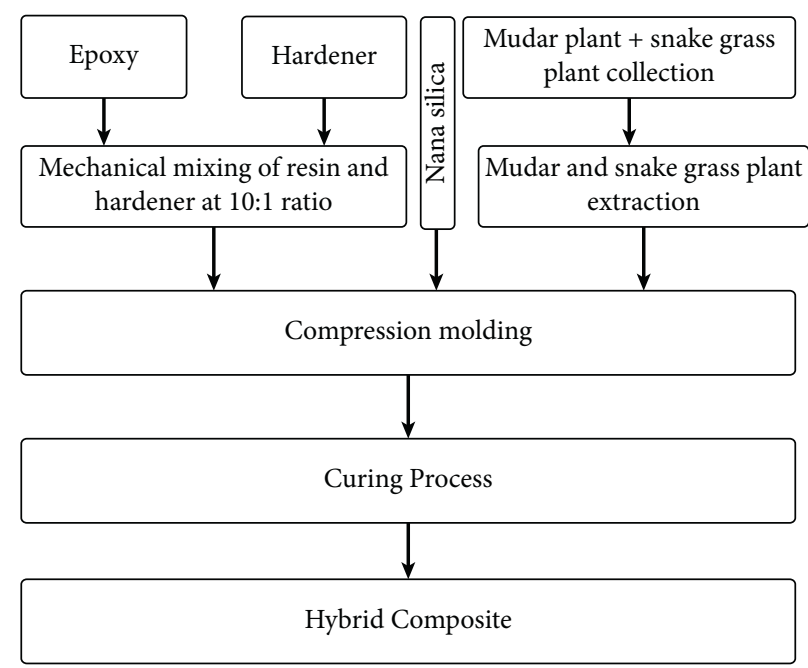

Figure 1: Composite fabrication process.

TABle 1: Properties of the fibers.

\begin{tabular}{lcccccc}
\hline Fiber name & $\begin{array}{c}\text { Density }(\mathrm{g} / \\
\left.\mathrm{cm}^{3}\right)\end{array}$ & $\begin{array}{c}\text { Diameter } \\
(\mu \mathrm{m})\end{array}$ & $\begin{array}{c}\text { Gage length } \\
(\mathrm{mm})\end{array}$ & $\begin{array}{c}\text { Tensile strength } \\
(\mathrm{MPa})\end{array}$ & $\begin{array}{c}\text { Tensile modulus } \\
(\mathrm{GPa})\end{array}$ & $\begin{array}{c}\text { Elongation } \\
(\%)\end{array}$ \\
\hline $\begin{array}{l}\text { Calotropis gigantea [23] } \\
\text { Sansevieria ehrenbergii }\end{array}$ & 0.56 & 125 & 50 & 382 & 9.7 & 2.1 \\
{$[24]$} & 0.887 & $20-250$ & $10-50$ & $50-585$ & $1.5-7.67$ & $2.8-21.7$ \\
\hline
\end{tabular}

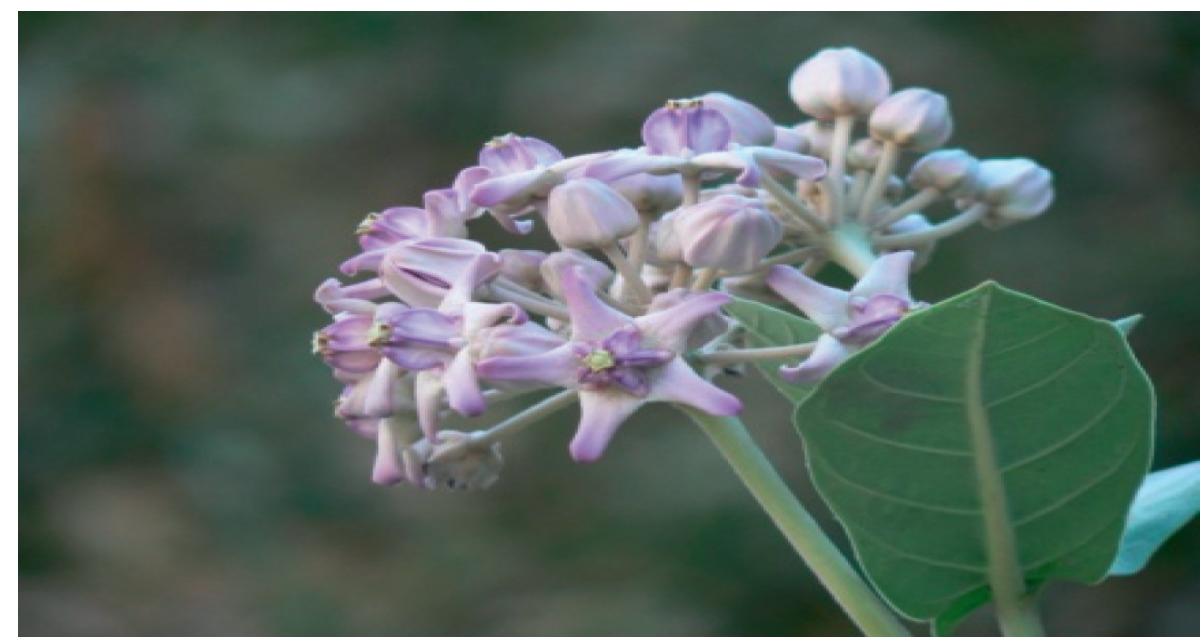

Figure 2: Calotropis gigantea.

sheets were placed at the top and bottom. A spacer frame was employed to lay the fiber on the mold. The different combinations of fabricated samples are shown in Table 2.

\section{Experimental Procedure}

3.1. Chopped Fiber-Reinforced Nano-Silica Composite Material Preparation. The samples were fabricated with $10 \%, 20 \%$, $30 \%$, and $40 \%$ volume fractions of fibers with $3 \%$ of nano-silica. The compression molding technique was employed to fabricate the samples. The fibers were cut into $5 \mathrm{~mm}$ to $8 \mathrm{~mm}$ lengths. Extracted fibers were kept in the oven at $70^{\circ} \mathrm{C}$ for 6 hours to remove the moisture content. The matrix solution was formed by mixing the epoxy and hardener in the ratio of $10: 1.3 \%$ of nano-silica was mixed with matrix and hardener for better propagation. The mixer was poured into the fiber and then the mold was closed. Pressure was applied to the mold to get the sample compacted. The remaining mixture was applied to the unfinished parts. Meanwhile, the composite plate was squeezed and compacted with a hand to remove the bubbles from the plate. The composite plate was left to cure for 20-24 hours until it was completely dry. A determined quantity of epoxy resin and hardener was employed for varying volume fractions of fibers. 


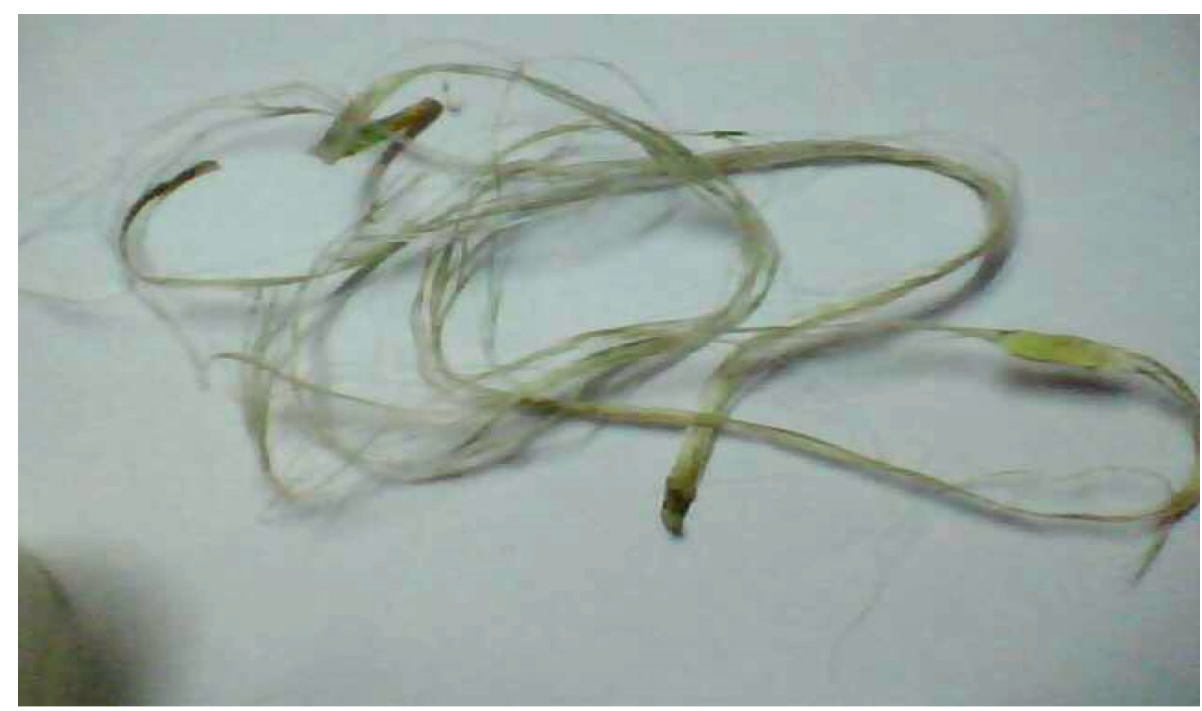

FIgURE 3: Extracted mudar fiber.

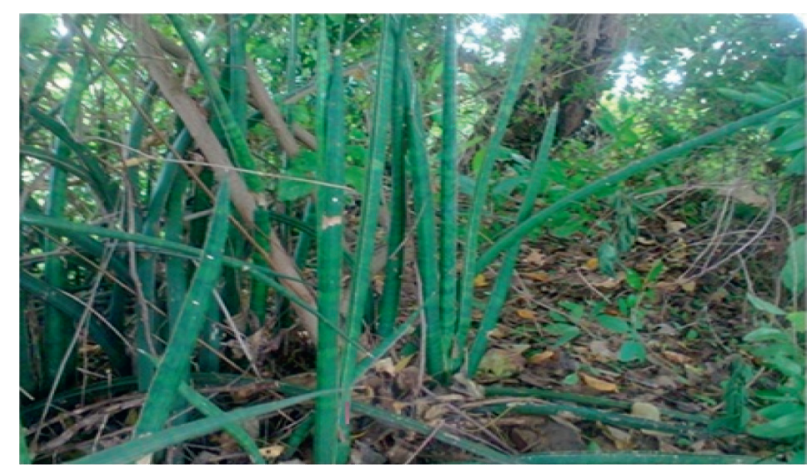

FIgURE 4: Sansevieria ehrenbergii.

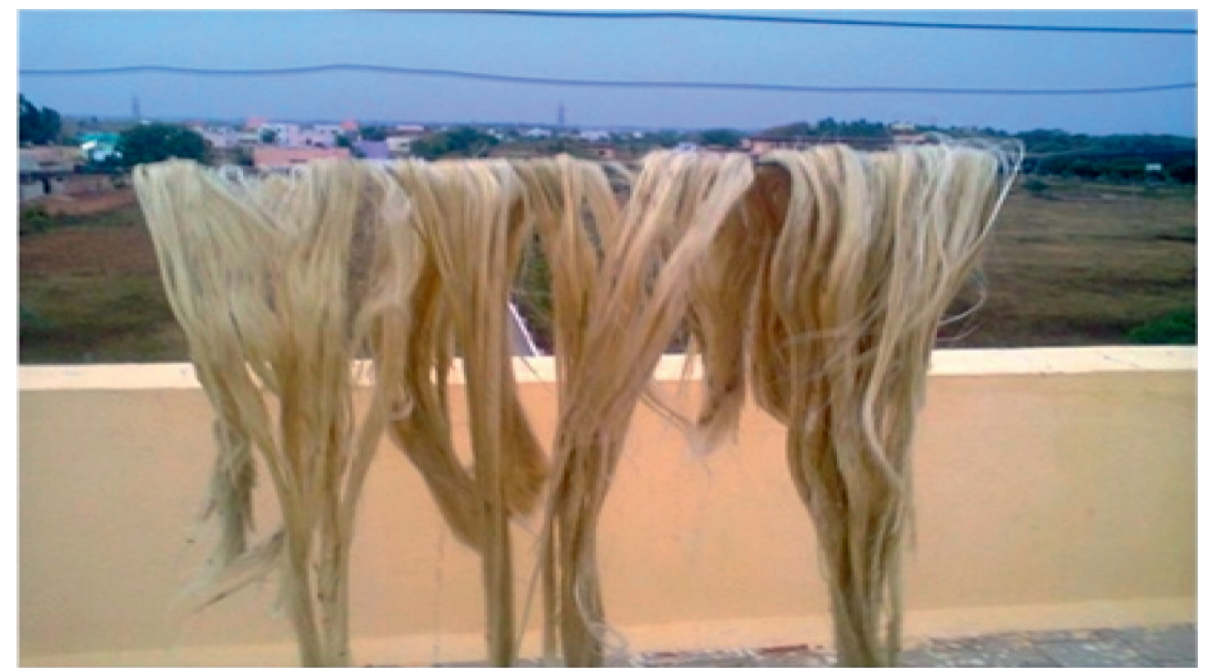

FIGURE 5: Extracted snake grass fiber. 


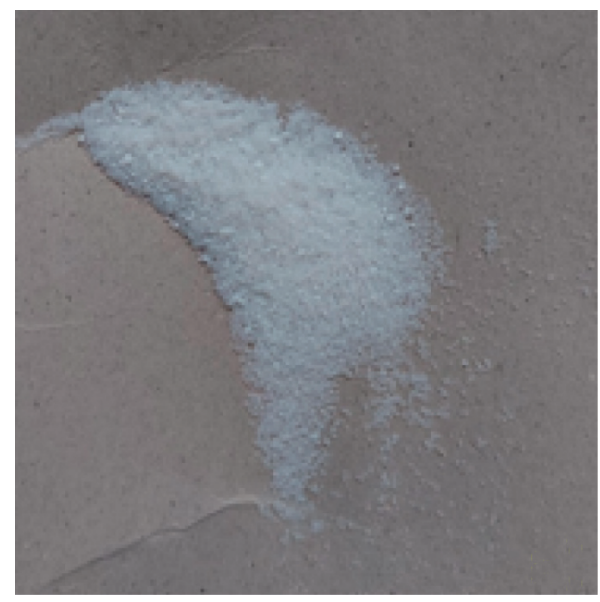

(a)

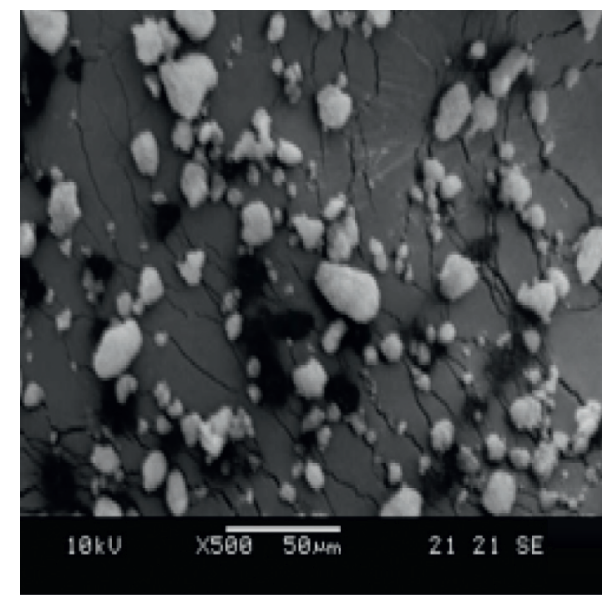

(b)

FIgURE 6: (a) Image of nano-silica. (b) SEM image of nano-silica.

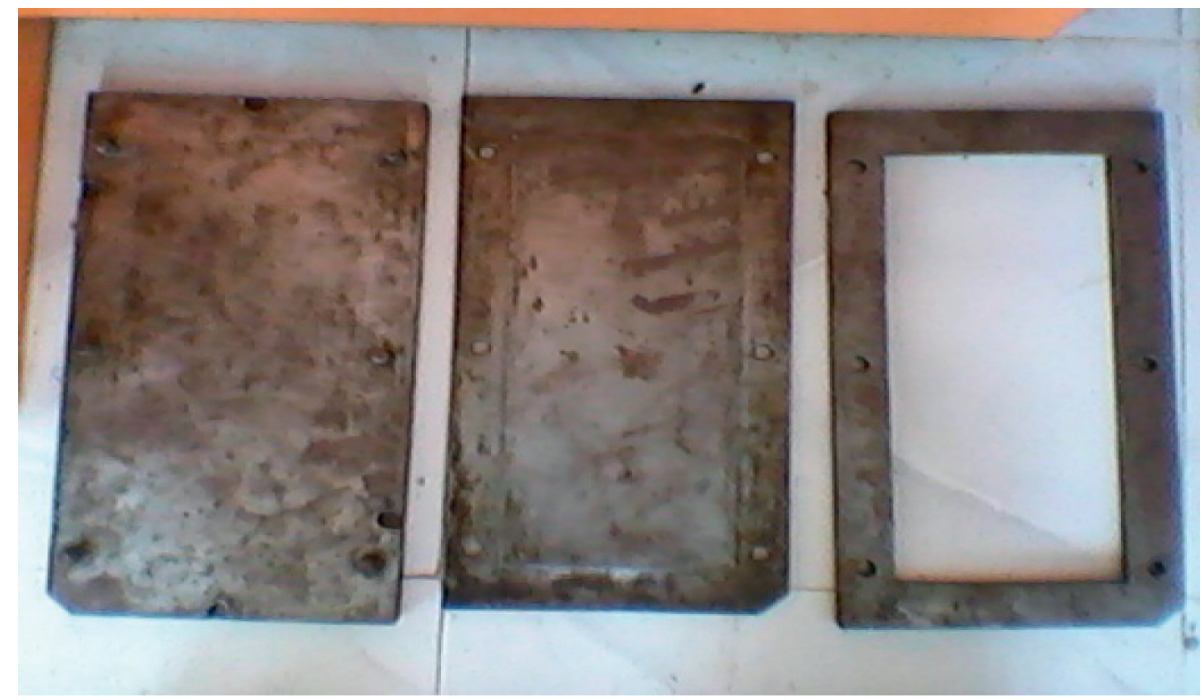

FIgURE 7: Steel die mold.

3.2. Specimen for Testing. The mechanical properties were analyzed after preparing the samples. The composite boards were cut into the standard test specimens ( 5 specimens were prepared for each testing to get an average value). Handsaws and other tools were used in the cutting process. All specimens tested were conditioned according to ASTM standards. The test specimens were kept in a room with a temperature of $23^{\circ} \mathrm{C} \pm 2^{\circ} \mathrm{C}$ with $50 \%$ of relative humidity for 40 hours before starting the test. All of the tests were carried out in a typical laboratory environment with a temperature of $23^{\circ} \mathrm{C}$ and relative humidity of $50 \%$.

3.3. Mechanical Testing. Following manufacture, the test specimens were put through a series of ASTM-required mechanical testing. Tensile, impact, and flexural test specimens with ASTM standard and dimensions are listed in Table 3.
3.4. Tensile Test (ASTM D3039). Once the curing process was done on the developed composite, a wire cutting instrument was employed to make the specimens into the required dimensions. The tensile test specimen was made as per ASTM D3039 (Figure 8); the testing specimen has a length of $250 \mathrm{~mm}$ and width of $25 \mathrm{~mm}$. The item was held in the grips of an Instron universal tester with a gage length of 100 millimeters. The ultimate tensile strength and tensile modulus of the composite were determined from the stressstrain diagram.

3.5. Flexural Test (ASTM D790). After the fiber-reinforced composite was cured, the specimens were cut into the required dimension with the aid of a wire cutting machine. The flexural test specimen was made following ASTM D790 (Figure 9); the composite was cut into the required dimension of $154 \mathrm{~mm}$ in length and $13 \mathrm{~mm}$ in width. The 
TABLE 2: Composition of fabricated samples.

\begin{tabular}{lccc}
\hline Sample ID & & Composition \\
& Epoxy (\%) & Fiber (MF + SGF) (\%) & Nano-silica (\%) \\
\hline Sample 1 & 87 & 10 & 3 \\
Sample 2 & 77 & 20 & 3 \\
Sample 3 & 67 & 30 & 3 \\
Sample 4 & 57 & 40 & 3 \\
\hline
\end{tabular}

TABLE 3: Test specimen standards with dimension.

\begin{tabular}{lccc}
\hline S. No & Type of testing & Standard used & Specimen dimension \\
\hline 1 & Tensile testing & ASTM D3039 & $250 \mathrm{~mm} \times 25 \mathrm{~mm} \times 2.5 \mathrm{~mm}$ \\
2 & Flexural testing & ASTM D790 & $154 \mathrm{~mm} \times 13 \mathrm{~mm} \times 3 \mathrm{~mm}$ \\
3 & Impact testing (Izod) & ASTM D4812 & $64 \mathrm{~mm} \times 12.7 \mathrm{~mm} \times 3.2 \mathrm{~mm}$ \\
\hline
\end{tabular}

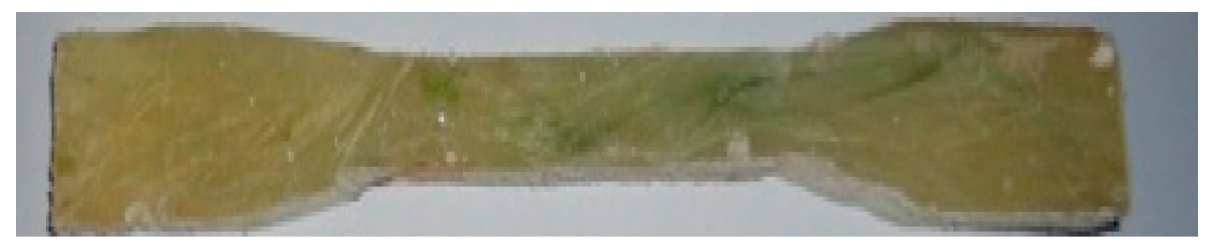

FIgURE 8: Specimen for tensile test.

specimen was fixed tightly with the Instron testing machine for measurement. The ultimate flexural strength of the specimens was measured from the stress-strain graph.

3.6. Impact Test (ASTM D4812). This test was done to measure the impact resistance of the developed composite. The amount of energy required to initiate the crack and keep it up to fracture is called impact. This test may be used to assess whether a material fulfills specified impact qualities or to compare materials for overall toughness. The specimens were prepared according to ASTM D4812 standard. The test sample is shown in Figure 10.

\section{Results and Discussion}

Previous sections covered the preparation of these composites as well as the tests that were undertaken on them. Here are the findings of several characterization tests. Tensile strength, flexural strength, and impact strength have all been investigated and analyzed.

4.1. Tensile Test. Table 4 shows the tensile properties of epoxy/SGF/MF with nano-silica hybrid composite. From the table, it was clear that sample 3 (67\% epoxy with $30 \%$ fiber volume fraction with $3 \%$ nano-silica) produces maximum tensile properties $\left(45 \mathrm{~N} / \mathrm{mm}^{2}\right)$ compared with other volume fractions. Hence, fiber volume fractions and nano-silica influenced the tensile strength of the developed composite. It was observed that the addition of fiber with the epoxy matrix improves the mechanical properties to the certain level. Fiber percentage more than $30 \%$ decreases the matrix-fiber adhesion, leading to the decrease in mechanical properties.
Also, increased fiber content beyond $30 \%$ will increase the void percentage in the developed composite materials.

4.2. Flexural Test. Flexural strength also called as bending strength can be measured using a 3-point flexural testing procedure. Flexural strength of the developed composites is listed in Table 5. The samples start to crack when the load exceeds the strength of developed samples. The flexural strength $\left(51 \mathrm{~N} / \mathrm{mm}^{2}\right)$ of sample 3 is more compared to the remaining developed samples. The presence of mudar fiber, snake grass fiber, and nano-silica increases the flexural strength. The higher flexural strength enhances the loadbearing capacity of samples. Flexural strength variation is very similar to tensile strength results. Adhesion between matrix and fiber reduces when the fiber percentage is more than $30 \%$. It does not allow a significant improvement for further addition of fiber in the sample.

4.3. Impact Test. The impact test determines the material's capacity to sustain abrupt shock loads. This test is carried out using an XJJU-50 impact testing machine. The mechanism comprises a loaded striker with set kinetic energy when released. The load will be removed once the specimen manufactured according to the specifications is retained in the machine. The amount of energy absorbed would be shown on display.

The impact strength of developed samples is listed in Table 6. From Table 6, sample 3 (67\% resin $+30 \%$ fiber $+3 \%$ nano-silica) produces the highest impact strength compared to other developed composites. Hence, sample 3 could be the suitable material for high damping and vibration-related applications. 


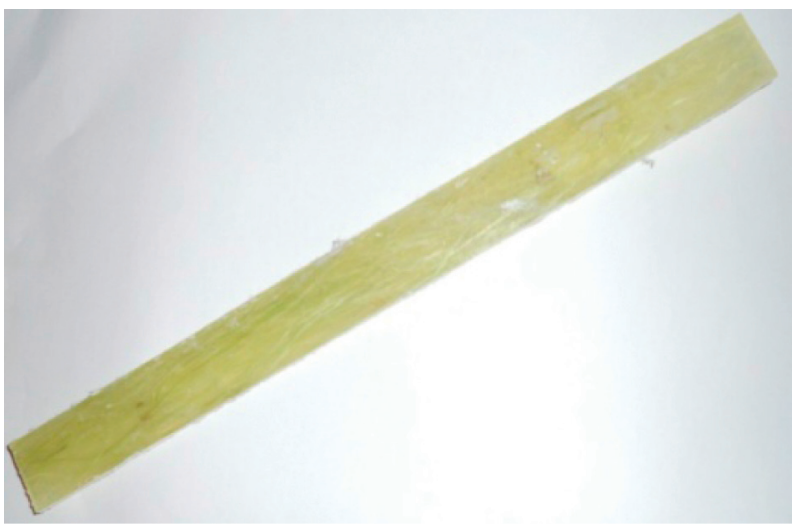

FIgURE 9: Specimen for flexural test.

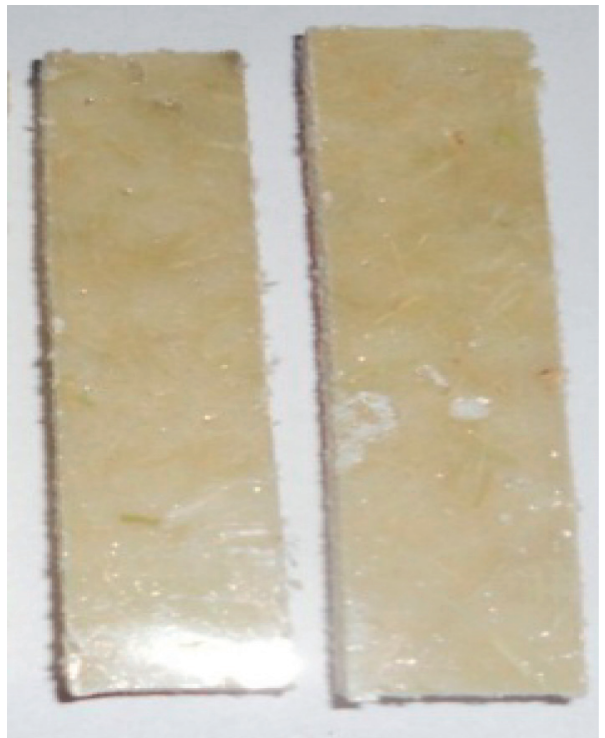

Figure 10: Specimen for impact test.

TABle 4: Tensile test result.

\begin{tabular}{lccc}
\hline Sample ID & Breaking load $(N)$ & Ultimate stress $\left(\mathrm{N} / \mathrm{mm}^{2}\right)$ & Max. displacement $(\mathrm{mm})$ \\
\hline Sample 1 & 1315 & 28 & 3.5 \\
Sample 2 & 1610 & 36 & 3.7 \\
Sample 3 & 2760 & 45 & 3.4 \\
Sample 4 & 1448 & 38 & 3.2 \\
\hline
\end{tabular}

4.4. SEM Investigation. The surface characteristics of developed samples were analyzed by using a scanning electron microscope (SEM). Samples were prepared with gold sputter coating for conducting purposes. A fractured tensile sample is shown in Figure 9. Sample 3 produces better mechanical properties that show proper bonding between matrix and fiber, resulting in improved tensile, flexural, and impact properties. The crack content and void content are less compared with other samples. Nano-silica increased the flexibility of the matrix, which led to the movement of the mixture inside the fiber wall and around the surface of the fiber. This phenomenon increases the mechanical properties.

Figure 11(a) shows the fractured surface of the sample, which indicates that the surface has matrix fracture, fiber fracture, and fiber pullout. Fiber pullout happens due to the poor adhesive of fiber and matrix. The fiber carries the load until it gets fractured which improves the mechanical properties. Figure 11 (b) depicts the matrix penetration inside the fiber walls, which increases the fiber-matrix attachment. 
TABLE 5: Flexural test result.

\begin{tabular}{lccc}
\hline Sample ID & Breaking load $(N)$ & Ultimate stress $\left(N / \mathrm{mm}^{2}\right)$ & Max. displacement $(\mathrm{mm})$ \\
\hline Sample 1 & 198 & 31 & 10.5 \\
Sample 2 & 182 & 35 & 11.5 \\
Sample 3 & 455 & 51 & 7.1 \\
Sample 4 & 204 & 39 & 3.2 \\
\hline
\end{tabular}

TABLE 6: Impact test results.

\begin{tabular}{lr}
\hline Sample ID & Impact strength (J) \\
\hline Sample 1 & 2.94 \\
Sample 2 & 3.33 \\
Sample 3 & 4.50 \\
Sample 4 & 2.80 \\
\hline
\end{tabular}

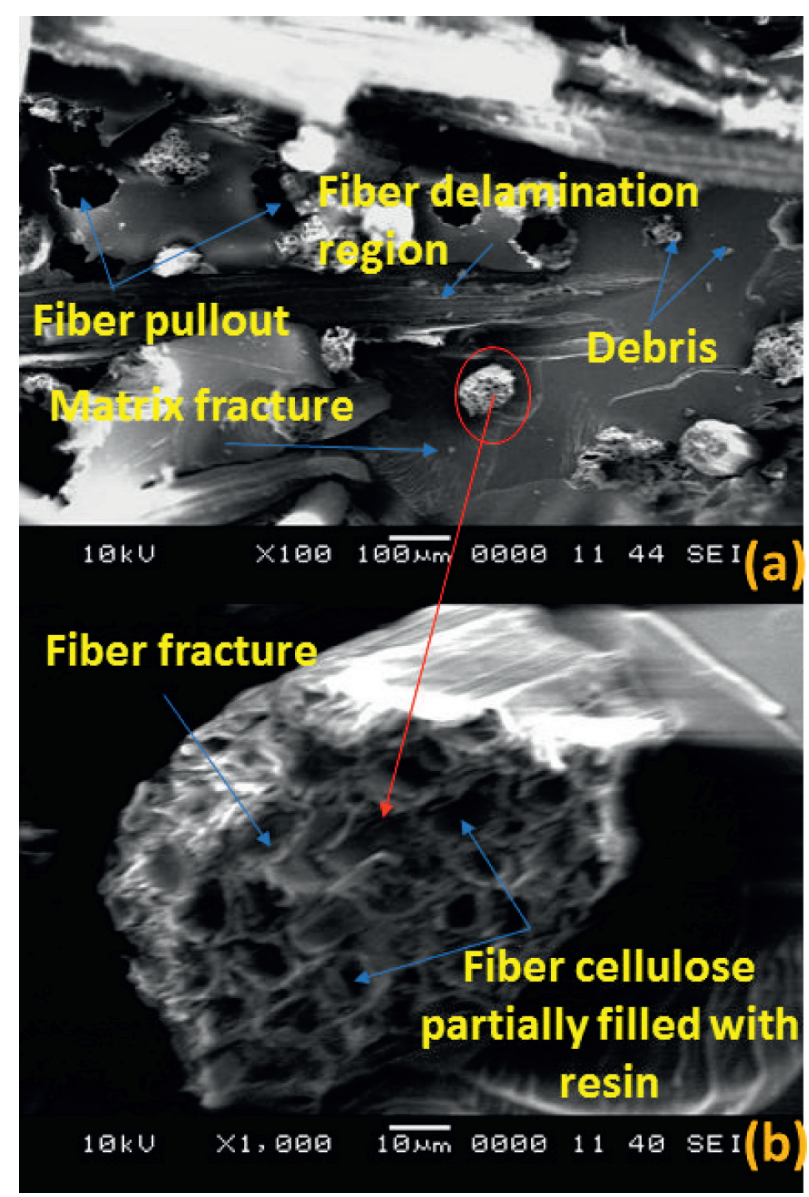

Figure 11: $(\mathrm{a}, \mathrm{b})$ Tensile fractured surface morphology of sample 3.

\section{Conclusion}

The following are the results derived from the experimental research of snake grass fiber and mudar fiber-reinforced epoxy with nano-silica filler composites.

This study demonstrates the successful fabrication of nano-silica incorporation with natural fiber-reinforced epoxy composites with varying fiber percentages using the hand layup technique. It has been discovered that differing volume fractions of fiber significantly affect the mechanical characteristics of composites, such as tensile, flexural, and impact strength. For varying breaking loads of fiber, tensile testing of composites is also strongly impacted. The strength of the fiber content at $30 \%$ is superior than the fiber content at $10 \%, 20 \%$, and $40 \%$. The incorporation of nano-silica (3\%) provided additional support to improve the properties of the prepared composite materials. The fiber content of $30 \%$ has a strong impact strength, which is followed by a reduction. 
The major ruptured mechanisms are matrix fracture, fiber fracture, and fiber pullout, which were substantiated by SEM images.

Fiber filled with resin increased the bonding strength between fiber and matrix. Moreover, incorporation of silica nanofiller increased the cohesive strength of the interlaminar structure. These behavioural changes strengthen the material at the optimum level of $30 \%$ hybrid fibers and 3\% nanosilica. The prepared sample 3 provides the maximum tensile strength of $45 \mathrm{MPa}$ and the flexural strength of $51 \mathrm{MPa}$. This result is more significant for fabricating products such as partition board, roof ceiling, circuit board, and roof gutter.

\section{Data Availability}

The data used to support the findings of this study are included within the article. Further data or information is available from the corresponding author upon request.

\section{Conflicts of Interest}

The authors declare that there are no conflicts of interest regarding the publication of this article.

\section{Acknowledgments}

The authors appreciate the support from Sharafuddin School, Hithadhoo, Maldives. The authors also thank Dr. Sivanthi Aditanar College of Engineering, Tuticorin, and this project was supported by Researchers Supporting Project number (RSP-2021/257), King Saud University, Riyadh, Saudi Arabia.

\section{References}

[1] M. Ramesh, C. Deepa, L. Rajeshkumar, M. Tamil Selvan, and D. Balaji, "Influence of fiber surface treatment on the tribological properties of Calotropis gigantea plant fiber reinforced polymer composites," Polymer Composites, 2021.

[2] S. Sathish, K. Kumaresan, L. Prabhu, and N. Vigneshkumar, "Experimental investigation on volume fraction of mechanical and physical properties of flax and bamboo fibers reinforced hybrid epoxy composites," Polymers and Polymer Composites, vol. 25, no. 3, pp. 229-236, 2017.

[3] S. Sathish, L. Prabhu, S. Gokulkumar, N. Karthi, D. Balaji, and N. Vigneshkumar, "Extraction, treatment and applications of natural fibers for bio-composites-a critical review," International Polymer Processing. Walter de Gruyter GmbH, vol. 36, 2021.

[4] C. Dash, A. Das, and D. Kumar Bisoyi, "Influence of pretreatment on mechanical and dielectric properties of short sunn hemp fiber-reinforced polymer composite in correlation with fine structure of the fiber," Journal of Composite Materials, vol. 54, no. 23, pp. 3313-3327, 2020.

[5] A. Felix Sahayaraj, M. Muthukrishnan, R. Prem Kumar, M. Ramesh, and M. Kannan, "-Review," IOP Conference Series: Materials Science and Engineering, vol. 1145, no. 1, Article ID 012069, 2021.

[6] P. Raveendran, S. V. Alagarsamy, C. Chanakyan, M. Meignanamoorthy, M. Ravichandran, and S. Sakthivelu, "A hybrid approach for predition of machining performances of glass fiber reinforced plastic (epoxy) composites," Surface Topography: Metrology and Properties, 2021.

[7] P. Wambua, J. Ivens, and I. Verpoest, "Natural fibres: can they replace glass in fibre reinforced plastics?" Composites Science and Technology, vol. 63, no. 9, pp. 1259-1264, 2003.

[8] A. V. Ratna Prasad and K. Mohana Rao, "Mechanical properties of natural fibre reinforced polyester composites: jowar, sisal and bamboo," Materials \& Design, vol. 32, no. 8-9, pp. 4658-4663, 2011.

[9] ASTM, International A. ASTM D638-14, Standard Test Method for Tensile Properties of Plastics, ASTM International, West Conshohocken, PA, US, 2015.

[10] K. M. M. Rao, A. V. R. Prasad, M. N. V. R. Babu, K. M. Rao, and A. V. S. S. K. S. Gupta, "Tensile properties of elephant grass fiber reinforced polyester composites," Journal of Materials Science, vol. 42, no. 9, pp. 3266-3272, 2007.

[11] ASTM I, Standard test methods for flexural properties of unreinforced and reinforced plastics and electrical insulating materials, ASTM D790-07, 2007.

[12] S. Jayabal and U. Natarajan, "Influence of fiber parameters on tensile, flexural, and impact properties of nonwoven coirpolyester composites," International Journal of Advanced Manufacturing Technology, vol. 54, no. 5-8, pp. 639-648, 2011, [Internet].

[13] G. Kalaprasad, K. Joseph, S. Thomas, and C. Pavithran, "Theoretical modelling of tensile properties of short sisal fibre-reinforced low-density polyethylene composites," Journal of Materials Science, vol. 32, no. 16, pp. 4261-4267, 1997.

[14] G. V. Vigneshwaran, I. Jenish, and R. Sivasubramanian, "Design, fabrication and experimental analysis of pandanus fibre reinforced polyester composite," in Advanced Materials Researchvol. 984-985, , pp. 253-256, Trans Tech Publ, 2014.

[15] G. L. Devnani and S. Sinha, "Effect of nanofillers on the properties of natural fiber reinforced polymer composites," Materials Today: Proceedings, vol. 18, pp. 647-654, 2019.

[16] N. Sapiai, A. Jumahat, M. Jawaid, M. Midani, and A. Khan, "Tensile and flexural properties of silica nanoparticles modified unidirectional kenaf and hybrid glass/kenaf epoxy composites," Polymers, vol. 12, no. 11, Article ID 2733, 2020.

[17] B. Suresha, G. S. Divya, G. Hemanth, and H. M. Somashekar, "Physico-mechanical properties of nano silica-filled epoxybased mono and hybrid composites for structural applications," Siliconindia, vol. 13, pp. 2319-2335, 2021.

[18] P. Madhu, M. R. Sanjay, P. Senthamaraikannan, S. Pradeep, S. S. Saravanakumar, and B. Yogesha, "A review on synthesis and characterization of commercially available natural fibers: part-I," Journal of Natural Fibers, vol. 16, no. 8, pp. 1132-1144, 2019a.

[19] V. K. Thakur and A. S. Singha, "Natural fibres-based polymers: part I-mechanical analysis of Pine needles reinforced biocomposites," Bulletin of Materials Science, vol. 33, no. 3, pp. 257-264, 2010.

[20] R. Vijay, D. Lenin Singaravelu, A. Vinod et al., "Characterization of raw and alkali treated new natural cellulosic fibers from Tridax procumbens," International Journal of Biological Macromolecules, vol. 125, pp. 99-108, 2019a.

[21] S. M.R., S. Siengchin, J. Parameswaranpillai, M. Jawaid, C. I. Pruncu, and A. Khan, "A comprehensive review of techniques for natural fibers as reinforcement in composites: preparation, processing and characterization," Carbohydrate Polymers, vol. 207, pp. 108-121, 2019.

[22] R. Ganesamoorthy, R. Meenakshi Reddy, T. Raja et al., "Studies on mechanical properties of kevlar/napier grass fibers reinforced with polymer matrix hybrid composite," Advances 
in Materials Science and Engineering, vol. 2021, Article ID 6907631, 2021.

[23] A. Ashori and Z. Bahreini, "Evaluation of Calotropis gigantea as a promising raw material for fiber-reinforced composite," Journal of Composite Materials, vol. 43, no. 11, pp. 1297-1304, 2009.

[24] T. P. Sathishkumar, P. Navaneethakrishnan, and S. Shankar, "Tensile and flexural properties of snake grass natural fiber reinforced isophthallic polyester composites," Composites Science and Technology, vol. 72, no. 10, pp. 1183-1190, 2012. 